\title{
UAV DIRECT GEOREFERENCING APPROACH IN AN EMERGENCY MAPPING CONTEXT. THE 2016 CENTRAL ITALY EARTHQUAKE CASE STUDY.
}

\author{
F. Chiabrando ${ }^{1}$, F. Giulio Tonolo ${ }^{1, *}$, A. Lingua $^{2}$ \\ ${ }^{1}$ Politecnico di Torino, DAD, Torino, Italy - (filiberto.chiabrando, fabio.giuliotonolo)@ polito.it \\ ${ }^{2}$ Politecnico di Torino, DIATI, Torino, Italy - andrea.lingua@ polito.it
}

\author{
Commission I, ICWG I/II
}

KEY WORDS: UAV, Direct Georeferencing, PPK, Emergency Mapping, Earthquake, Accuracy

\begin{abstract}
:
UAVs platform are increasingly deployed by first responders and local stakeholders to get a first overview of disaster affected areas with a high level of detail and different off-nadir angle configurations. Through a rapid mapping approach, the acquired data (video sequences or pictures) are analysed to extract information on damages to buildings and infrastructures with the goal to support the Search and Rescue operations. The specific focus of the paper is on evaluating the expected benefits (from the rapid mapping perspective) deriving from a direct georeferencing approach when using UAV with RTK capabilities. Specifically, data acquired by a fixed wing eBee RTK platform by SenseFly over the areas affected by the earthquake that hit central Italy in 2016 have been processed to compare the positional accuracies of orthoimagery generated by means of a direct georeferencing approach (without any GPC) with and without a post-processing kinematic solution. The results highlight that an RTK-enabled platform allows to achieve orthoimagery positioning accuracy values up to few centimeters without the need of any control point. In the conclusion session the operational implications of a PPK-based approach versus a standard direct georeferencing are critically discussed.
\end{abstract}

\section{INTRODUCTION}

In the aftermath of a disaster remotely sensed imagery, generally acquired by very high resolution optical sensors installed on satellite platforms, are commonly exploited to analyse the impact over the affected areas (Voigt et al., 2016). Considering that the maximum level of detail of vertical satellite imagery (ground sample distance up to $0.3 \mathrm{~m}$ as of March 2019) may be limiting in discriminating lower damage grades, UAVs platform are increasingly deployed by first responders and local stakeholders to get a first overview of the affected areas with a high spatial resolution (up to few centimetres) and different offnadir angles (FSD, 2016). The acquired data (generally video sequences or pictures) are analysed to extract information on damages to buildings and infrastructures, adopting both manual or semi-automated approaches, with the goal to support the Search and Rescue (SAR) operations (Boccardo et al, 2015). In order to maximize the effectiveness of the extracted added value information, the geospatial component shall be properly taken into account, through a fast but rigorous photogrammetric data processing aimed at generating $3 \mathrm{D}$ models and orthoimages of the surveyed areas. In rapid mapping, i.e. "the fast provision (hours-days) of geospatial information supporting emergency management activities immediately following an emergency event" as per the definition adopted by the Copernicus Emergency Management Service () European Union, 20122019), the timeliness of the delivery of post-event orthoimagery is a crucial factor.

Different approaches have already been tested by the research group in previous works in order to meet this objective, e.g. the use of multitemporal acquisitions, the exploitation of embedded GPS/GNSS receiver or the use of double grid acquisition with a very small number of GCPs (Chiabrando et al., 2017a; Aicardi et al., 2016; Rupnik et al., 2015). The specific focus of this paper is on the adoption of a direct georeferencing approach, that enables a faster i) data acquisition, allowing to neglect the prepositioning and measurement of artificial markers, and ii) imagery processing, limiting the human intervention. Of course the direct georeferencing is a viable option only if the UAV technical features allow the required positioning accuracies to be met. The paper is therefore aimed at analysing the performance of a PPK (Post Processing Kinematic) approach in terms of positional accuracy of both the platform itself during the flight and of the orthoimagery generated by means of a direct georeferencing approach. In order to fulfil this purpose, the 2016 central Italy case study has been extensively analysed and discussed. Section 2 is focused on the Materials (Case Study, UAV platform) and Methods (PPK and photogrammetric processing) while the results are described in Section 3. The main outcomes are discussed in Section 4.

\section{MATERIALS AND METHODS}

\subsection{Case study}

Starting from August 2016 the area of central Italy is under stress due to a series of significant earthquakes, as shown in Figure 1: the main shocks were registered respectively on the 24th of August, 26th and 30th of October 2016 (INGV, 2017). Immediately after the first event the Geomatics research group of the Polytechnic University of Turin and the connected Disaster Recovery Team (DIRECT) were active in carrying out UAV acquisitions in cooperation with the Remotely Piloted Aircraft Systems (RPAS) group of the Italian Firefighters (Chiabrando, 2017b; Feliziani, 2018). In order to monitor the evolution of the situation due to the continuous aftershocks in the same areas, several aerial survey campaigns have been planned and carried out since then, adopting and testing several

\footnotetext{
* Corresponding author
} 
platforms types (including multirotor and fixed wings) in order to evaluate their specific features and performance. The area of interest analysed in this manuscript covers the village of Accumoli and is highlighted by the red box in Figure 2 .

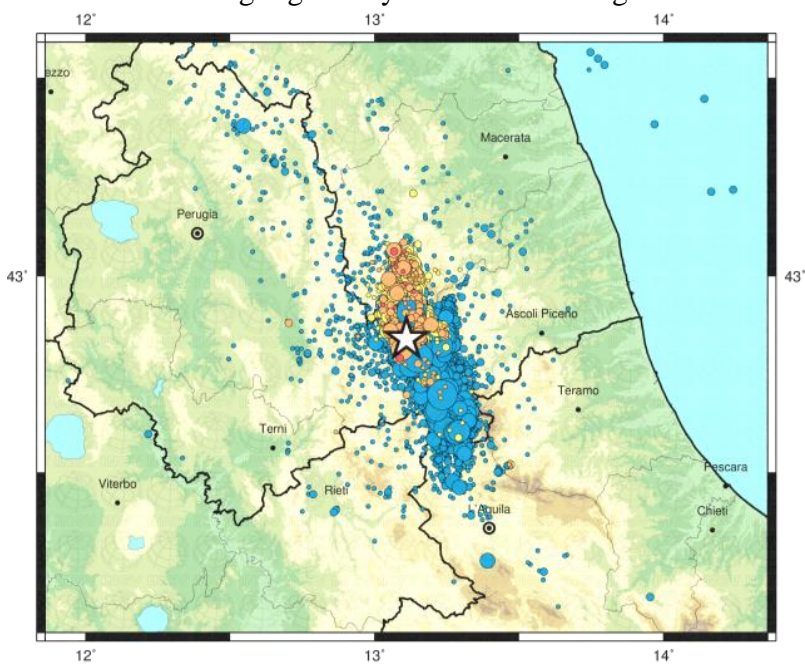

Figure 1. Earthquakes in the last 90 days before the 30 Oct 2016 event (Source: $\mathrm{INGV}^{1}$ ). Symbol size is proportional to the event magnitude. The symbol color (red $=1$ hour; orange $=24$ hours; yellow $=72$ hours; blue $=$ previous 90 days) identifies the time of occurrence of the earthquakes with respect to the 30 Oct 2016 event (white star).

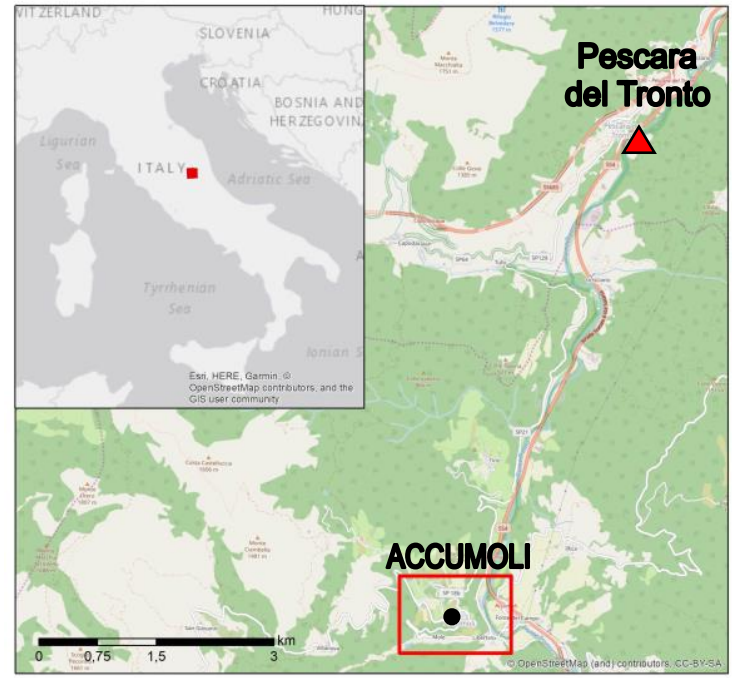

Figure 2. Area of interest covering the Accumoli village (red square)

\subsection{UAV platform and ancillary data}

The data processed for this research were acquired by a platform with an on-board double frequency GNSS, namely the eBee RTK by SenseFly over the Village of Accumoli (RI) during the DIRECT team stage held on July 2018. DIRECT is a team of students, researchers and professors of the Polytechnic University of Turin that aims to operate in the Disaster Management domain, including environmental vulnerability

\footnotetext{
${ }^{1}$ http://cnt.rm.ingv.it/en/event/8863681\#
}

assessment, immediate response to emergencies, post-disaster surveys and Capacity Building. The DIRECT team was founded in 2012 to actively contribute to the protection of the territory and the architectural and environmental heritage, especially during environmental emergencies or in the case of heritage subject to conservation risks. During the summer of 2018 a stage of the team was carried out in the area of central Italy to document the earthquake-affected areas exploiting a multisensor data survey, including the eBee RTK. This platform enables i) the real-time correction of the on-board GNSS position and the image geotags with the RTK (Real Time Kinematic) option or ii) the data post-processing after the flights using the PPK option.

On July 17, 2018, 303 images were acquired by the aforementioned eBee RTK equipped with a S.O.D.A camera (sensor size 1", focal length $10.6 \mathrm{~mm}$, resolution $18.2 \mathrm{Mp}$ ) and flying in autonomous mode (line of sight) at a planned flight height of around $100 \mathrm{~m}$ (expected average GSD $=0.03 \mathrm{~m}$ ) with lateral overlapping of $60 \%$ and longitudinal overlapping of $75 \%$. The flight planning was carried out using the eMotion 3 as shown in Figure 3.

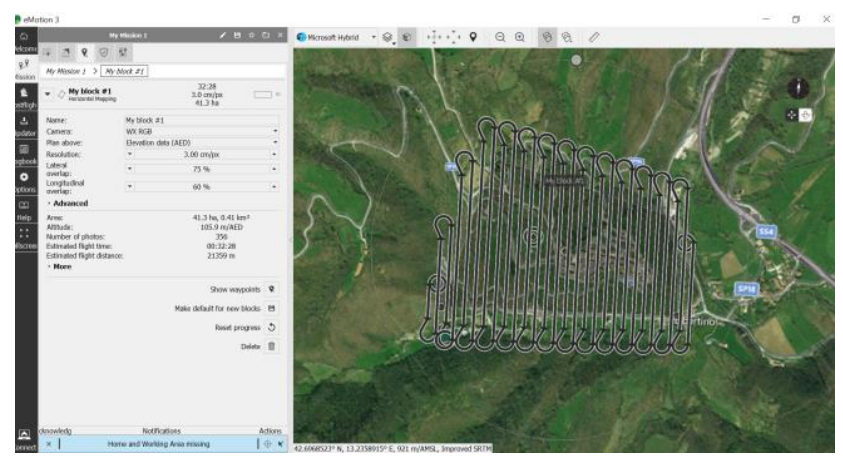

Figure 3. The flight planning interface in eMotion 3.

eMotion 3 allows to easily manage all the flights operations from the planning of the take-off up to the landing phase. Different automatic tools support the operator during the choice of the technical settings, ensuring a constant GSD even in nonplanar areas. This is probably the most important advantage of eMotion since it exploits the Digital Elevation Model (DEM) of the areas to be surveyed to dynamically adjust the UAV flight height in order to maintain to a constant value the GSD of each strip. An example of acquired image and related level of detail is provided in Figure 4.

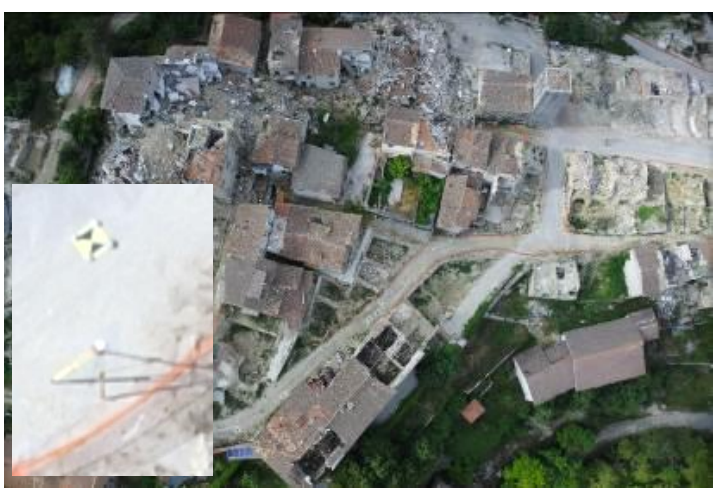

Figure 4. Example of raw image and related level of detail (bottom left, artificial $0.4 \times 0.4 \mathrm{~m}^{2}$ marker and GNSS receiving station mounted on a tripod) 
Due to the unavailability of a proper GNSS master station with RTK capabilities required to apply on-the-fly GPS/GNSS corrections, the PPK option has been set up before the flight in order to post-process the data after the acquisitions. Specifically, the GPS/GNSS observations acquired by a Geomax Zenith 35 Pro GNSS receiver (https://geomaxpositioning.com/) in Pescara del Tronto ( $7 \mathrm{~km}$ from Accumoli, red triangle in Figure 2) have been exploited, allowing to reestimate the flight path and calculate the new image geotags (Figure 5).

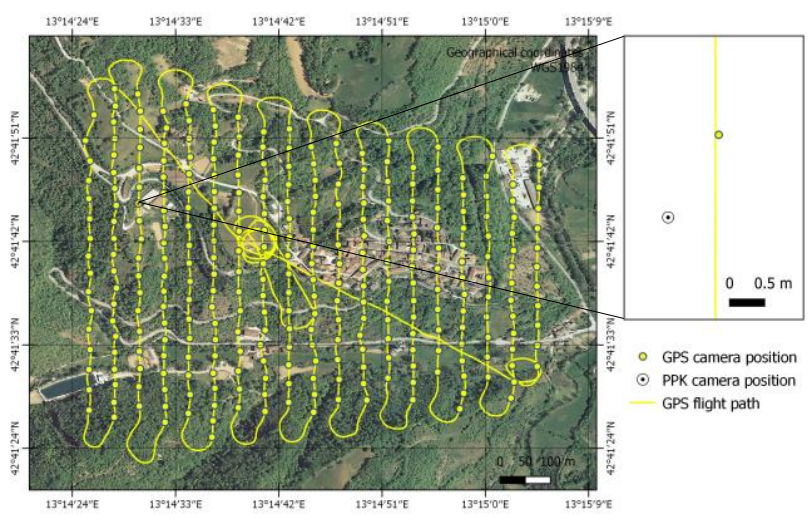

Figure 5. eBee RTK flight path and camera positions. In the detail, comparison among raw and PPK camera position.

Additionally, since the main objective from the Geomatics point of view is to evaluate the geometric accuracy of the generated products, 31 points - to be used as Ground Control Points (GCPs) and/or Check Points (CPs) - have been measured on the ground.

The survey of the points was performed using a NRTK (Network Real Time Kinematic) approach thanks to the HxGM smartnet service from Hexagon (https://hxgnsmartnet.com/). This approach allows to apply the corrections of the Hexagon Italian GNSS network in real time and to measures 3D coordinates with an average accuracy of about $0.002 \mathrm{~m}$.

Both natural (e.g. manmade features clearly visible from vertical imagery, example shown in Figure 6, left) and artificial markers $\left(0.4 \times 0.4 \mathrm{~m}^{2}\right.$ removable soft plastic panels with ad-hoc patterns, example shown in Figure 6, right) have been used.
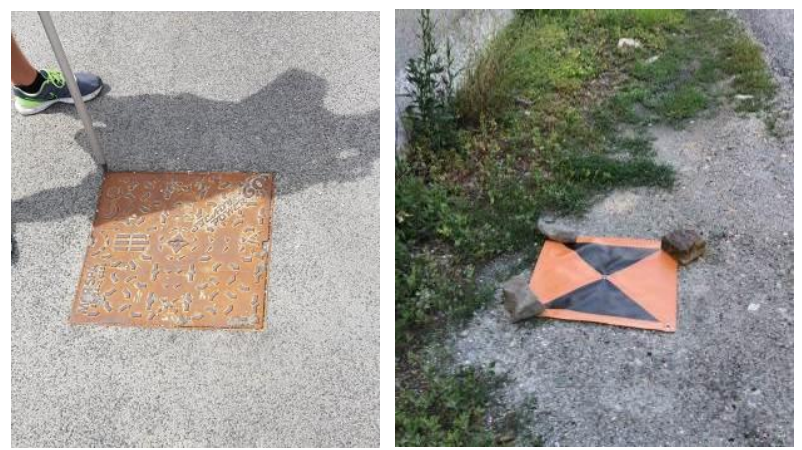

Figure 6. Examples of existing (left) and artificial (right) markers measured on the ground and used as GCP and/or CP.

\subsection{PPK data processing}

The PPK post-processing was carried out using the eMotion drone's flight management software (version 3.5.0) by
SenseFly, which automatically handles the georeferencing and the preparation of the images required for the subsequent step. The process carried out by the software is fully automatic, but a few parameters (i.e. the 3D coordinates of the base station and the estimated accuracy after the processing) need to be accurately cross-checked in order to obtain reliable results. The pipeline allows to combine the UAV GNSS acquired data, that are stored in the log file during the flight, with the GPS/GNSS data of the reference station on the ground.

The geographic coordinate of the base station and the technical details of the employed GNSS antenna (including the related height from the ground marker, Figure 7, top) are required. After this step the software is able to estimate the accuracy of the post-processed coordinates (from $5 \mathrm{~m}$ to $0.05 \mathrm{~m}$, Figure 7, bottom).
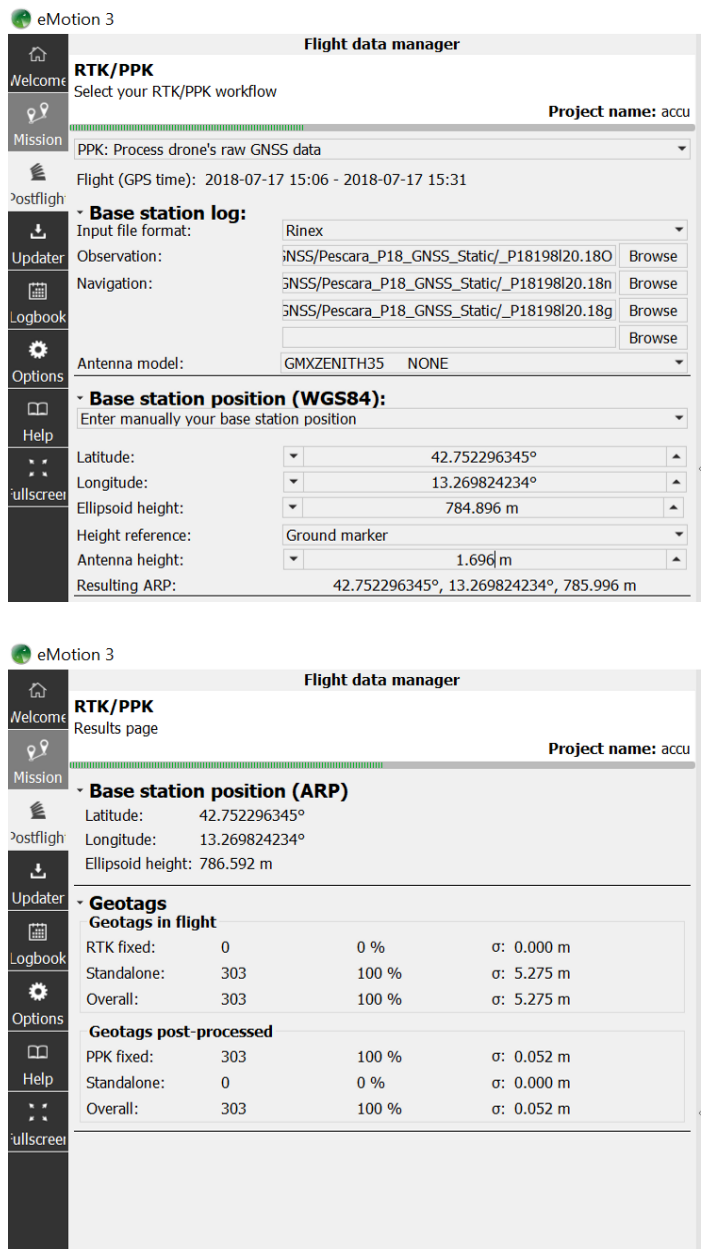

Figure 7. eMotion3 PPK processing windows. The GNSS base station input data: observation, 3D coordinates and antenna height (top). The estimated accuracy of the Geotags after the PPK process (vs the ones measured during the flight, bottom).

The photogrammetric processing, i.e. the images orientation, the point cloud extraction and the digital surface model (DSM) and orthoimagery generation was carried out in the Pix4DMapper Pro software (version 4.0.25).

The aforementioned processing have been carried out on a desktop PC with the following technical features: Intel ${ }^{\circledR}$ Core $^{\mathrm{TM}}$ i7-2600 CPU $3.40 \mathrm{GHz}, 64$ bit OS, 24 GB RAM, 2 NVIDIA GeForce GTS 450 GPUs. The details of the different strategies used during the photogrammetric tests are reported in the next section. 


\subsection{Photogrammetric processing}

After the PPK processing the images were processed using a standard and well established photogrammetric workflow based on the traditional SfM (Structure from Motion, Luhmann, 2013) approach (Förstner, 2016), including:

1. Camera calibration and Image orientation (relative/absolute)

2. Dense matching and Mesh generation

3. Digital Surface Model (DSM) and Orthoimagery generation

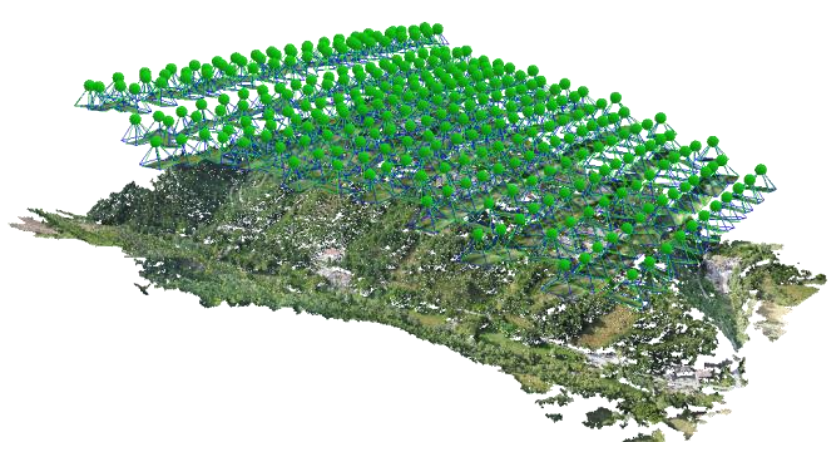

Figure 8. 3D view of the photogrammetric block (303 images).
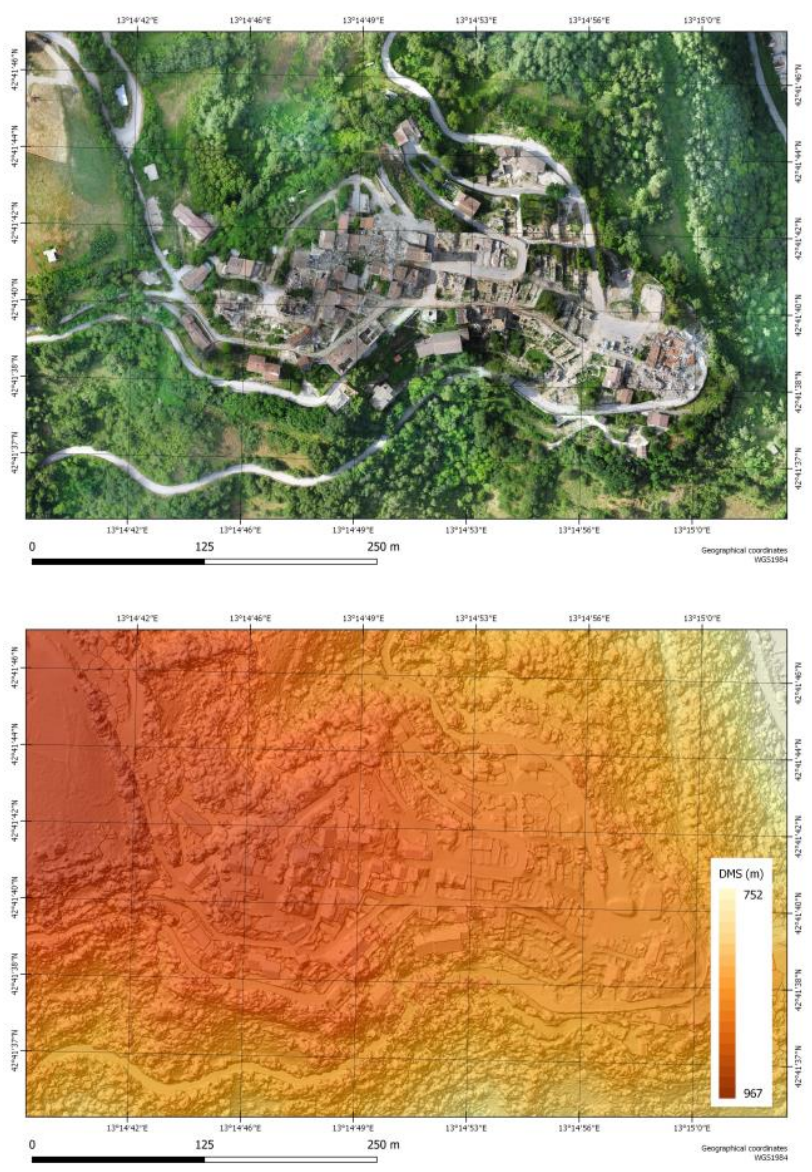

Figure 9. Mosaicked orthoimage (top) and DSM (bottom) covering the village of Accumoli. GSD $=\sim 0.05 \mathrm{~m}$
During the initial step the software extracts the interior and exterior parameters of the cameras and create a sparse point cloud using features automatically extracted from the images. In this step of the processing three different approaches can be adopted: i) to exploit the on-board GNSS data, ii) to use the PPK geotags or iii) to ignore the geographic information stored in the exif file, excluding it from the processing. Tie Points (TPs) are extracted and an automatic bundle block adjustment is carried out to create the first projective reconstruction or 'sparse model' and to calibrate the employed camera (Figure 8).

The user can manually introduce the measured 3D coordinates (in an absolute reference system) of the GCPs or CPs identified on the images through the manual editor: the model reoptimization and transformation to absolute coordinates steps are subsequently carried out.

From the user perspective, this is the most time consuming task (when a direct georeferencing approach is not adopted), despite the availability of semi-automatic tools to support this step (automatic matching, on-the-fly update of the orientation) and the possibility to automatically import the measured coordinates.

The analysis of the residuals on both GCPs and CPs (available in the quality report generated after the re-optimization) is needed to evaluate if a fine-tuning or correction of the point collimation is required. The following step is the dense matching that requires - as standard setting - each pixel to be identified in at least three images using a 1:2 scaling.

Additionally, a 3D mesh can be generated from the dense 3D point cloud to have a uniform shape of the surveyed area. The final step of the workflow is the production of DSMs and Orthophotos (Strecha, 2012): related examples are shown in Figure 9.

The data and imagery acquired over Accumoli have been processed in order to compare the positional precision of the orthoimagery generated by means of a direct georeferencing approach (without any GCP) with initial camera /GNSS position calculated with and without PPK solution. The accuracy of the photogrammetric process has been estimated using the 31 surveyed points as Check Points (Table 1, bold).

\begin{tabular}{|c|c|c|c|}
\hline $\begin{array}{l}\text { Test } \\
\text { ID }\end{array}$ & $\begin{array}{c}\text { Camera } \\
\text { positions }\end{array}$ & $\begin{array}{c}\mathrm{n} . \\
\text { GCP }\end{array}$ & $\begin{array}{l}\mathrm{n} . \\
\mathrm{CP}\end{array}$ \\
\hline NOPPK_NO GPC & \multirow{3}{*}{$\begin{array}{c}\text { Raw } \\
\text { GNSS }\end{array}$} & $\mathbf{0}$ & 31 \\
\hline NOPPK_5GCP & & 5 & 26 \\
\hline NOPPK_13GCP & & 13 & 18 \\
\hline PPK_NO GPC & \multirow{3}{*}{ PPK } & $\mathbf{0}$ & 31 \\
\hline PPK_5GCP & & 5 & 26 \\
\hline PPK_13GCP & & 13 & 18 \\
\hline
\end{tabular}

Table 1. Summary of the adopted photogrammetric processing configurations. Direct georeferencing approaches highlighted in bold.

Additionally, the same data have been re-processed with two different configurations using the measured points as GCPs and/or CPs. As detailed in Table 1, two further test have been carried out, using 5 and 13 GCPs and the remaining points as CPs (respectively 26 and 18). Figure 10 shows the spatial distribution of the employed points configuration. 

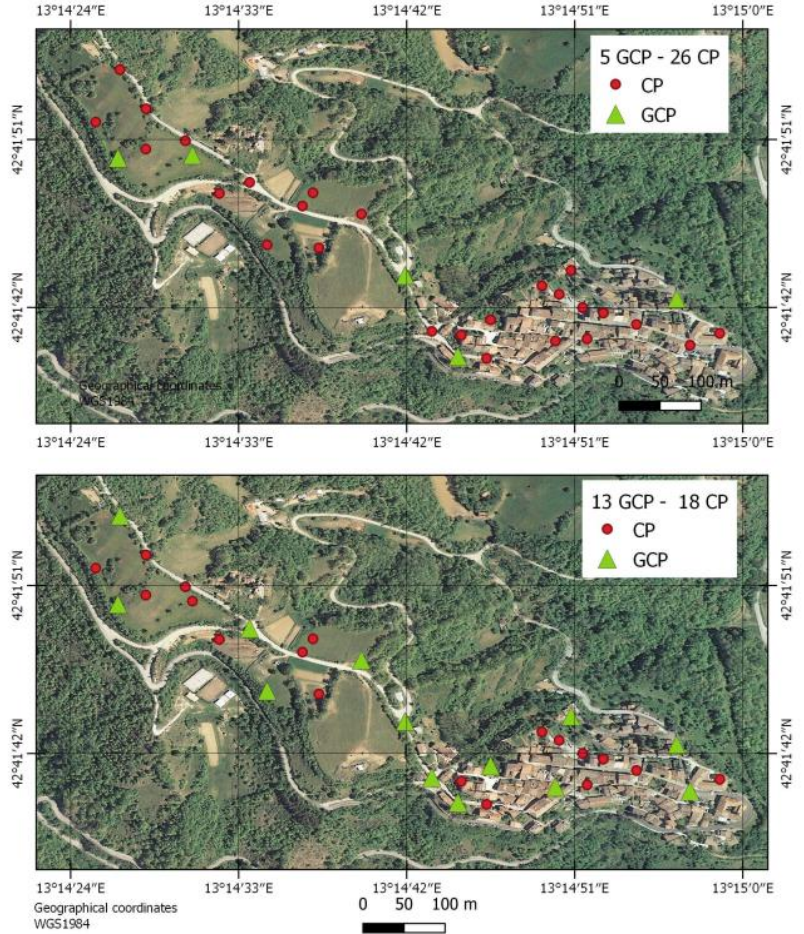

Figure 10. Adopted GPC (green triangles) and CP (red circles) configuration. $5 \mathrm{GCP}+26 \mathrm{CP}$ (top) and $13 \mathrm{GCP}+18 \mathrm{CP}$ (bottom)

The overall photogrammetric workflow required about 265 minutes (excluding - when required - the time for GCP/CP collimation that is user dependent) on a PC with the technical specifications described in paragraph 2.3 and average settings (optimal point density, 1:2 image downsampling, medium resolution $3 \mathrm{D}$ mesh).

\section{RESULTS}

The positional accuracies achieved with the approaches described in the previous chapter are summarised in Table 2.

The direct georeferencing approach (without any GCP) was the main focus of the analysis and highlighted the clear impact of a PPK based approach which enables a horizontal accuracy of $\sim 0.035 \mathrm{~m}$ (vs $1.39 \mathrm{~m}$ with raw GNSS data) and a vertical accuracy of $0.090 \mathrm{~m}$ (vs $3.95 \mathrm{~m}$ ). The mean values of 3D discrepancies on CPs highlight the presence of systematic shifts that could be minimized using only 1 GCP, leading to horizontal and vertical accuracies below $0.15 \mathrm{~m}$ and $0.5 \mathrm{~m}$ respectively for the Raw GNSS case.

As expected (Tomaštík et al., 2019; Benassi et al, 2017), the adoption of 5 GCPs (distributed on the borders and in the middle of the flight stripes) leads to 3D accuracies values of few centimetres also with raw GNSS data and a limited impact on the PPK based approach.

With 13 GCPs, the PPK based accuracies improved to values of few millimetres (while the only benefits for the processing based on raw GNSS data are related to the $\mathrm{Z}$ component).

From the qualitative point of view, no significance difference among the PPK and RAW GNSS approaches can be highlighted in terms of typical mosaicking issues, that are generally due to dense point cloud errors (especially in dense/high vegetation areas). Such issues are more evident on linear features like road edges and power lines (examples shown in Figure 11).

\begin{tabular}{|c|c|c|c|c|c|c|c|}
\hline & \multicolumn{3}{|c|}{ Raw GNSS } & \multicolumn{3}{|c|}{ PPK } \\
\hline & & Mean & StDev & RMS & Mean & StDev & RMS \\
\hline \multirow{3}{*}{$\begin{array}{c}\text { Direct } \\
\text { Georef. } \\
0 \text { GCP } \\
31 \mathrm{CP}\end{array}$} & $X$ & -1.103 & 0.108 & 1.108 & -0.006 & 0.028 & 0.029 \\
\hline & Y & -0.84 & 0.130 & 0.853 & 0.014 & 0.014 & 0.020 \\
\hline & Z & -3.917 & 0.468 & 3.945 & -0.082 & 0.030 & 0.087 \\
\hline \multirow{3}{*}{$\begin{array}{l}5 \mathrm{GCP} \\
26 \mathrm{CP}\end{array}$} & $X$ & 0002 & 0.031 & 0.031 & 0.002 & 0.026 & 0.026 \\
\hline & $\mathrm{Y}$ & 0.003 & 0.016 & 0.017 & -0.003 & 0.013 & 0.013 \\
\hline & 7 & 0.002 & 0.070 & 0.069 & 0.008 & 0.025 & 0.026 \\
\hline \multirow{3}{*}{$\begin{array}{c}13 \mathrm{GCP} \\
18 \mathrm{CP}\end{array}$} & & 0.005 & 0.024 & 0.025 & 0.000 & 0.002 & 0.002 \\
\hline & $\mathbf{V}$ & 0.000 & 0.012 & 0.012 & 0.000 & 0.001 & 0.001 \\
\hline & 7 & -0.003 & 0.032 & 0.032 & 0.000 & 0.003 & 0.003 \\
\hline
\end{tabular}

Table 2. 3D positional accuracies in terms of Mean, Standard Deviation (StDev) and Root Mean Square Error (RMS) using a direct georeferencing approach and the two GPCs/CPs configurations shown in Figure 10, with and without PPK processing.
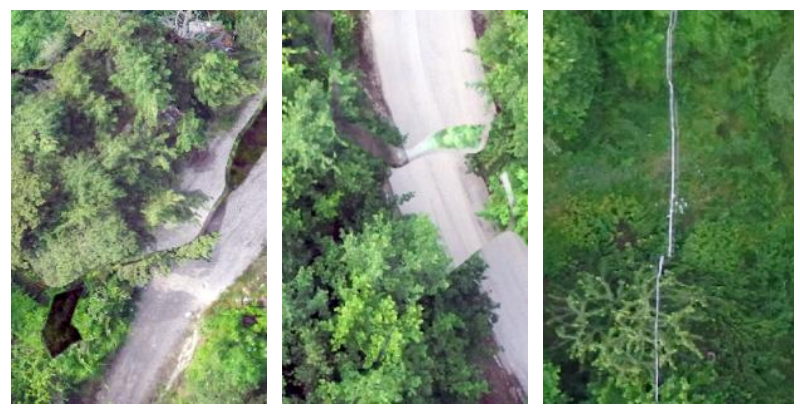

Figure 11. Example of mosaicking issues in areas with dense/high vegetation

From the rapid mapping perspective, the level of detail (GSD = $\sim 0.05 \mathrm{~m}$ ) and the possibility to acquire also oblique imagery, allow the intrinsic limitations or satellite vertical imagery to be overcome. Figure 12 clearly demonstrates the possibility to accurately assess the damages to buildings, according to recently proposed international standards on building damage scale (Cotrufo et al, 2018), also adopted by the Copernicus Emergency Management Service (ㄷ) European Union, 20122019) and the International Working Group on Satellite-based Emergency Mapping ${ }^{2}$ (IWG-SEM).

One of the derivative products that can also support the rapid mapping tasks is the classified point cloud, where all the point features are assigned to pre-defined categories, specifically: ground, road surface, high vegetation, building, human made object (examples of road surface and high vegetation classes are shown in Figure 13). In this specific case, the presence of debris can be quickly highlighted by the human made object class, while the building class can be exploited to focus the damage assessment analysis only on the built-up areas.

\footnotetext{
2 http://www.un-spider.org/sites/default/files/IWG_SEM_ Guidelines_Building\%20Damage\%20Assessment_v1.0.pdf
} 


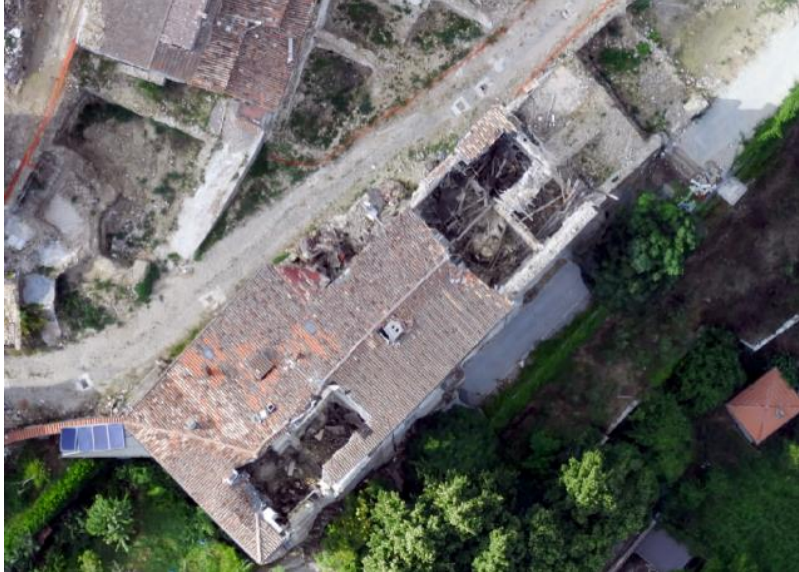

Figure 12. Detail of an earthquake-effected building
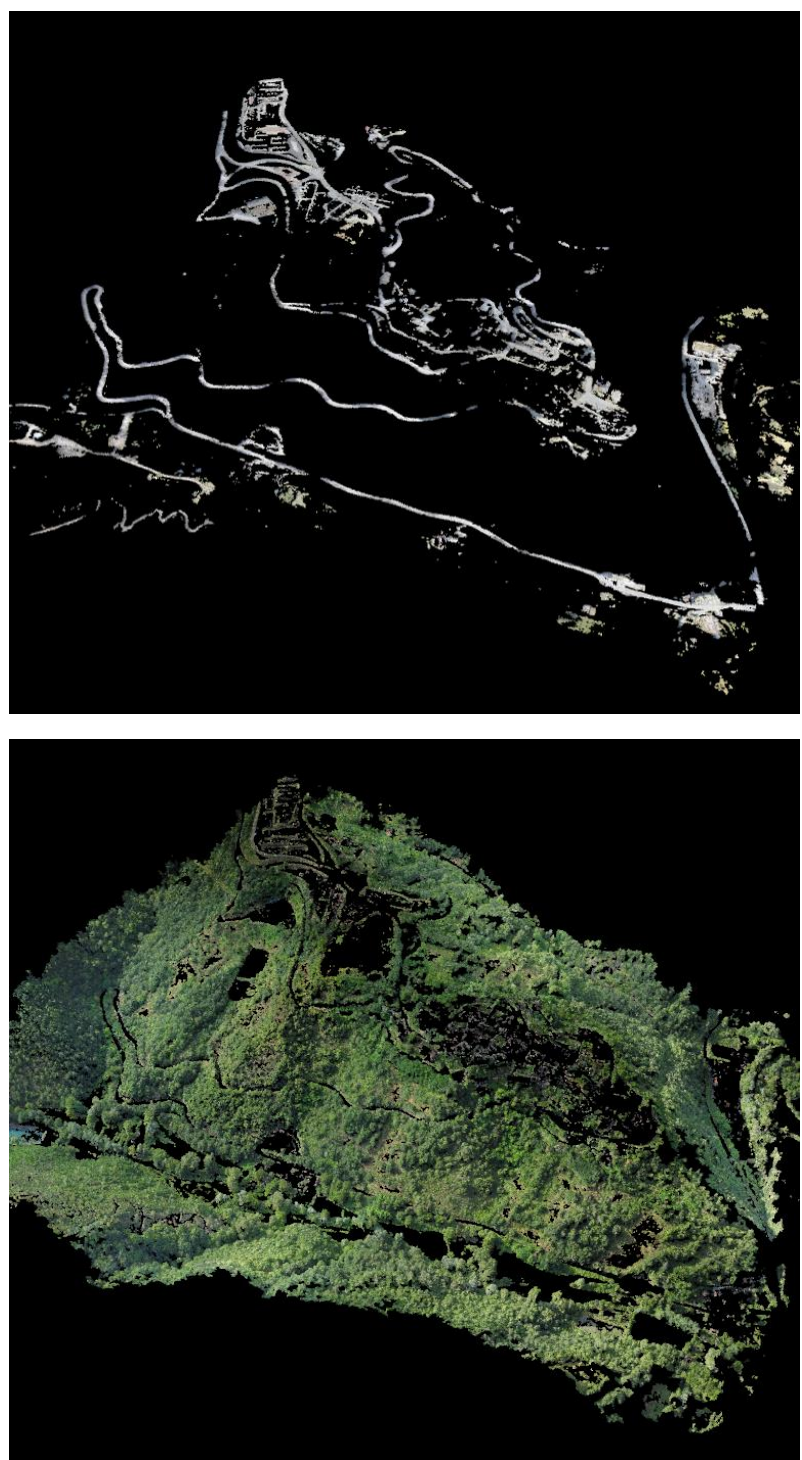

Figure 13. Point cloud classification: road surface (top) and high vegetation (bottom) classes.

\section{CONCLUSIONS}

The results described in chapter 3 highlight that PPK corrected data enable the production of accurate (both planimetric and altimetric accuracy lower than $0.1 \mathrm{~m}$ ) orthoimagery and derivative products (e.g. 3D mesh, classified dense point cloud, DSM). In the framework of rapid mapping, where the timeliness is a crucial factor, the possibility to completely neglect the preliminary operations related to the materialisation and measurement of targets on the ground is a clear advantage. Nevertheless, a PPK approach requires an additional expertise in the post-processing phase, since GNSS observations acquired in the same period of the UAV survey shall be retrieved and properly processed, including ancillary technical information as the GNSS antenna type and elevation and the precise coordinates of the reference station. Alternatively, virtual reference station networks or GNSS permanent stations can be exploited when existing.

Additionally, a proper cost-benefit analysis should be carried out, especially considering that even using a cheaper non-RTK platform the horizontal accuracy that can be achieved without any GCP is below $1.5 \mathrm{~m}$. Similar horizontal positional error values allows to easily locate the earthquake affected infrastructure and to uniquely relate them to existing map data, e.g. authoritative National Mapping and Cadastre Agency data that are generally adopted by the national civil protection agencies.

An RTK approach could be also useful when complex areas need to be surveyed (steep obstacles and tight spaces), allowing the flight to be more coherent to the flight plan. For this reason, further tests have already been planned in order to confirm the outcomes of the results related to this specific case study, with the goal to exploit the RTK option during the UAV flights and to adopt the same accuracy validation workflow over different areas. It has to be highlighted that a GNSS (virtual) reference station should be available in real-time during the UAV survey. Operators on the ground should be therefore trained to meet this requirement and to cope with possible network issues (common in emergency situations).

\section{ACKNOWLEDGEMENTS}

The authors are grateful to the Direct team of the Polytechnic University of Turin for the acquisition and provision of the UAV and ancillary data related to the 2016 central Italy earthquake.

\section{REFERENCES}

Aicardi, I., Chiabrando, F., Grasso, N., Lingua, A. M., Noardo, F., \& Spanò, A. (2016). UAV photogrammetry with oblique images: first analysis on data acquisition and processing. The International Archives of the Photogrammetry, Remote Sensing \& Spatial Information Sciences, n 41, 835-842.

Benassi, F., Dall'Asta, E., Diotri, F., Forlani, G., Morra di Cella, U., Roncella, R., \& Santise, M. (2017). Testing accuracy and repeatability of UAV blocks oriented with GNSS-supported aerial triangulation. Remote Sensing, 9(2), 172.

Boccardo, P.; Chiabrando, F.; Dutto, F.; Giulio Tonolo, F.; Lingua, A. 2015. UAV Deployment Exercise for Mapping Purposes: Evaluation of Emergency Response Applications. Sensors 2015, 15, 15717-15737. doi:10.3390/s150715717 
Chiabrando, F., Lingua, A., Maschio, P., \& Losè, L. T. (2017a). The influence of flight planning and camera orientation in UAVs photogrammetry. A test in the area of Rocca San Silvestro (LI), TUSCANY. The International Archives of Photogrammetry, Remote Sensing and Spatial Information Sciences, $\mathrm{n}^{\circ} 42,163-170$.

Chiabrando F., Maschio P., Lingua A., Sammartano G., Spanò; A., Teppati Losè; L., Di Lolli A., Feliziani F., Firrincelli M., Fiorini M., Lorusso O., (2017b), "Modelli 3d metrici da uav per l'emergenza: supporto alle valutazioni preliminari qualiquantitative del danno. Il caso del terremoto in centro Italia 2016", Atti del Workshop UAV \& SAR: using drones in rescue operations, 29 Marzo, Roma

Cotrufo, S., Sandu C., Giulio Tonolo, F. \& Boccardo, P. 2018. Building damage assessment scale tailored to remote sensing vertical imagery, European Journal of Remote Sensing, 51:1, 991-1005, doi: 10.1080/22797254. 2018.1527662

Wolfgang Förstner, Bernhard P. Wrobel. 2016. Photogrammetric Computer Vision. Springer, ISSN 1866-6795 DOI 10.1007/978-3-319-11550-4

Feliziani F., Lorusso O., Ricci A., Massabò A., Di Lolli A., Colangeli A.,Fiorini M., (2018). Tecniche di realizzazione ed utilizzabilità di mappature e rilievi speditivi per analisi di impatto e gestione di uno scenario emergenziale: impieghi operativi di UAV. Atti Asita 2018, 27-28-29 Novembre Bolzano, pp. 489-492.

Förstner, W., Wrobel, B. P. 2016. Photogrammetric Computer Vision. Springer, ISSN 1866-6795 DOI 10.1007/978-3-31911550-4

FSD, Drones in Humanitarian Action: A Guide to the Use of Airborne Systems in Humanitarian Crises, 2016 https://irevolution.files.wordpress.com/2011/07/drones-inhumanitarian-actionemail.pdf

INGV (gruppo di Lavoro) sul Terremoto in centro Italia. 2017. Relazione sullo stato delle conoscenze sulla sequenza sismica in centro Italia 2016-2017 (aggiornamento al 2 febbraio 2017), doi: 10.5281/zenodo.267984

Luhmann, T., Robson, S., Kyle, S., \& Boehm, J. (2013). Closerange photogrammetry and $3 \mathrm{D}$ imaging. Walter de Gruyter.

Rupnik, E., Nex, F., Toschi, I., \& Remondino, F. (2015). Aerial multi-camera systems: Accuracy and block triangulation issues. ISPRS Journal of Photogrammetry and Remote Sensing, 101, 233-246.

Tomaštík, J., Mokroš, M., Surový, P., Grznárová, A., \& Merganič, J. (2019). UAV RTK/PPK Method-An Optimal Solution for Mapping Inaccessible Forested Areas? Remote Sensing, n 11(6), 721.

Voigt, S., Giulio-Tonolo, F., Lyons, J., Kučera, J., Jones, B., Schneiderhan, T., Platzeck, G., Kaku, K., Kumar Hazarika M., Czaran, L., Li, S., Pedersen, W., Kadiri James, G., Proy, C., Macharia Muthike, D., Bequignon, B., Guha-Sapir, D. (2016) Global trends in satellite-based emergency mapping, Science, Vol. 353, Issue 6296, pp. 247-252, DOI: 10.1126/science.aad8728 